\author{
EVS26 \\ Los Angeles, California, May 6-9, 2012
}

\title{
Reaching $10 \%$ renewable transportation fuels in 2020 by electric-vehicles in Styria/Austria
}

\author{
Gerfried Jungmeier ${ }^{1}$, Karl-Peter FELBERBAUER ${ }^{1}$, Martin BEERMANN ${ }^{1}$ \\ IJOANNEUM RESEARCH Forschungsgesellschaft $\mathrm{mbH}$, RESOURCES - Institute for Water, Energy and \\ Sustainability, Energy Research, Elisabethstraße 18/II, A-8010 Graz, \\ Tel.: +43 316 876-1313, E-mail: gefried.jungmeier@joanneum.at,Web:www.joanneum.at
}

\begin{abstract}
Electric-vehicles have the potential for a significant substitution of diesel and gasoline vehicles, and contribute to a reduction of greenhouse gas (GHG) and particulate matter emissions. According to the European Renewable Energy Directive, the share of renewable transportation fuels should be $10 \%$ in 2020 . In the project "Styrian e-mobility in 2020 " the potential for reaching the target of $10 \%$ renewable fuels in 2020 has been determined by analysing different implementation scenarios. Based on a life cycle analysis, GHG and particulate matter emissions from transport services have been calculated and their potential reductions in emissions by the introduction of electric vehicles by 2020 have been determined. Reaching the European target of $10 \%$ renewable fuels in the passenger car sector by 2020 is possible with 30,700 electric-vehicles ( $5 \%$ of passenger cars) if the share of the additional electricity is above $50 \%$ from renewable energy and the same amount of transportation biofuel of $7 \%$ used as today.
\end{abstract}

Keywords: LCA (Life Cycle Assessment), EV (electric vehicle), infrastructure, market introduction

\section{Motivation}

Electric-vehicles, as well as biofuels, have the potential for a significant substitution of diesel and gasoline vehicles. They can contribute to a reduction of greenhouse gas emissions (GHG) and particulate matter emissions in the transport sector, especially if they are powered by additional renewable electricity. In Austria (fuel consumption: $320 \mathrm{PJ} / \mathrm{a}$ ) and Styria (fuel consumption: $43 \mathrm{PJ} / \mathrm{a}$ of which $16 \mathrm{PJ} / \mathrm{a}$ for passenger cars) the amount of transportation biofuels, especially biodiesel and bioethanol blended to gasoline and diesel, was about $7 \%$ in 2009. According to the European Renewable Energy Directive, the share of renewable fuels should be $10 \%$ in 2020, where renewable electricity is counted with a factor of 2.5 .

\section{Content and objectives}

The GHG emissions in Styria in 2007 were 14.1 million tons $\mathrm{CO}_{2}$ equivalent (Mt $\mathrm{CO}_{2}$-eq) (transport $1.7 \mathrm{Mt} \mathrm{CO}_{2}$-eq, energy supply: $1.9 \mathrm{Mt}$ $\mathrm{CO}_{2}$-eq). The particulate matter emissions in 2007 were about 7,500 tons per year; of which $19 \%$ were emitted by the transport sector. In 2009 the Styrian passenger car stock was about 664,000 of which 43,529 were new passenger cars. The electricity demand in the year 2009 was about $8,300 \mathrm{GWh} / \mathrm{a}$, of which $61 \%$ was generated by renewable sources. The maximum power demand on a winter day at 11:00 clock was about 1,429 MW in the Styrian electricity grid. Due to the fact that Styria has a great additional potential of biomass and renewable electricity, biofuels and 
electric-vehicles can significantly contribute to a future sustainable transport sector in Styria.

The objective of "Styrian e-mobility in 2020" (Jungmeier et al., 2011) was to analyze the future prospects for the introduction of electric vehicles in Styria. Scenarios for electric vehicles were developed based on scenarios for the introduction of electric vehicles in Austria The model "emobility Styria 2020" was developed to investigate the possible implementation of electric-vehicles in Styria until 2020.

Furthermore, the 17 Styrian districts were assessed by their characteristics. Districts with "very good" and "good" framework conditions for the early introduction of electric-vehicles were identified. With the model "e-drive" the additional power and electricity demand was calculated. Moreover, the costs for transportation services were determined. Furthermore, based on a life cycle analysis, GHG and particulate matter emissions from transport services and their potential reductions in emissions by the introduction of electric-vehicles by 2020 were calculated.

In the analysis, four groups of early adopters of electric-vehicles were identified:

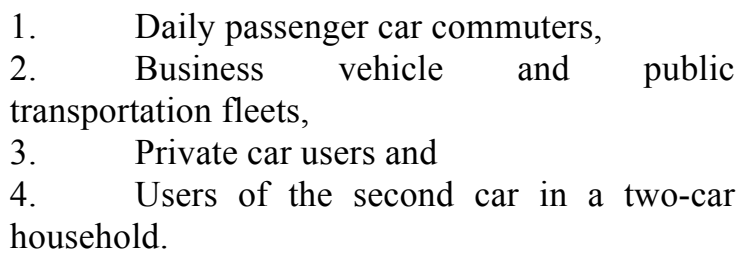

\section{Results and Discussion}

The analysis of five scenarios with three different types of electricity generation ("electricity mix Austria", "electricity from natural gas", "electricity mix renewable") and two charging strategies ("uncontrolled", "controlled") lead to the following results:

- Under favourable conditions, up to 30,700 electric-vehicles are possible in Styria by 2020 (i.e. $4.6 \%$ of the total car stock in 2009).

- The following six districts have "very good" framework conditions for the early introduction of electric-vehicles:

$\circ$ Deutschlandsberg,
$\bigcirc$ Feldbach,
$\bigcirc$ Graz,
$\bigcirc$ Graz-Umgebung,
$\bigcirc$ Leibnitz and
$\bigcirc$ Weiz.

- A reduction of the total energy demand for passenger cars in Styria from $4,481 \mathrm{GWh} / \mathrm{a}$ $(16 \mathrm{PJ} / \mathrm{a})$ to $4,331 \mathrm{GWh} / \mathrm{a} \quad(15.65 \mathrm{PJ} / \mathrm{a})$ is possible.

- The electricity demand for 30,700 electricvehicles is $98 \mathrm{GWh} / \mathrm{a}$, i.e. $1.2 \%$ of the current electricity demand in Styria.

- The maximum power demand in the Styrian electricity grid of about 1,429 MW at 11:00 clock is raised by $2,8 \mathrm{MW}$ for charging 30,700 electric-vehicles, i.e. $0,19 \%$ of the maximum power demand.

- The additional power demand during the evening peak at $17: 45$ is about $15.4 \mathrm{MW}$, increasing the current power demand at this time to $1,371 \mathrm{MW}$. This is still a little less than the current maximum power demand at 11:00.

- The maximum additional power demand is about $75 \mathrm{MW}$ in the night at about 22:45 clock.

- 30,700 electic-vehicles require about 38,500 charging stations by 2020 .

- The number of power plants required for the additional renewable electricity is:

- 1 large $20 \mathrm{MW}$ hydro power plant or

- 3 small hydro power plants each with $7 \mathrm{MW}$ or

- 23 wind turbines each with $2 \mathrm{MW}$ or

- 19 biogas plants each with $1 \mathrm{MW}$ or

- 500 large PV systems each with 200 $\mathrm{kW}$ or

- 24,000 small PV systems each with $15 \mathrm{~kW}$.

- The analysis of the currently built and planned new power plants in Styria by 2015 showed:

○ $95 \%$ of the additional produced electricity will be generated by natural gas and

- $5 \%$ of the additional produced electricity will be generated by renewable energy.

- The possible annual GHG emission reduction is (Figure 1) :

- $30,000 \mathrm{t} \mathrm{CO}_{2}$-eq/yr using "electricity from natural gas",

- 50,000 $\mathrm{t} \mathrm{CO}_{2}$-eq using an "electricity mix Austria" with 54\% renewable electricity and

- 75,000 t $\mathrm{CO}_{2}$-eq/yr an "electricity mix renewable". 
- These correspond to between 1.7 to $4.4 \%$ of the current GHG emissions from the transport sector in Styria.

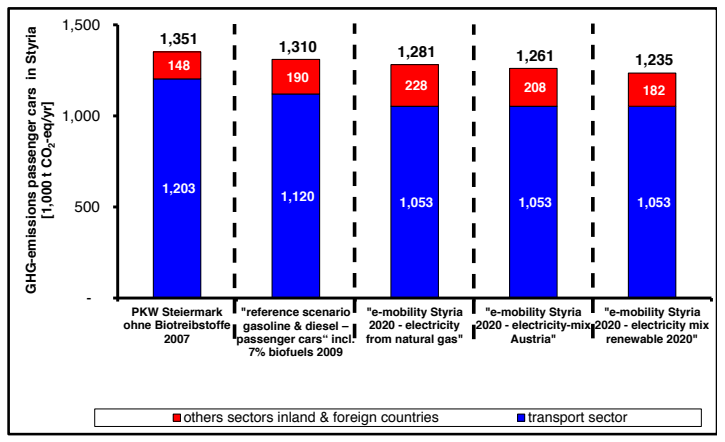

Figure 1: GHG-emissions by passenger cars in Styria

- The annual reduction of particulate matter emissions by replacing each 15,350 diesel and 15,350 gasoline passenger cars by 30,700 electric vehicles is estimated as $9.3 \mathrm{t}$ PM10/yr $(8.8 \mathrm{t} / \mathrm{yr}$ from diesel and $0.5 \mathrm{t} / \mathrm{yr}$ from gasoline cars). This is $4 \%$ of current particulate matter emissions from passenger cars in Styria.

- Reaching the European target of $10 \%$ renewable fuels in the passenger car sector by 2020 is possible with 30,700 electricvehicles, if the share of the additional electricity is above $50 \%$ from renewable energy and the same amount of transportation biofuel used as today. This is possible because the renewable electricity is counted with a factor of 2.5.

- The Styrian economy has a great potential for job creation (e.g., "Green Jobs") in all areas of the value chain during the life cycle of an electric-vehicle. The areas where job creation will be particularly interesting are:
- Automotive/Mobility,
- Energy and Environmental Technology and Renewable Energy,
$\circ$ Engineering/Construction and

\section{Acknowledgments}

The work is part of the project "Styrian emobility in 2020", funded by the Federal State of Styria in Austria - Department Science and Research.

\section{References}

Jungmeier, G., Felberbauer, K.-P., Beermann, M.; Report "Styrian e-mobility in 2020", Graz 2011

\section{Authors}

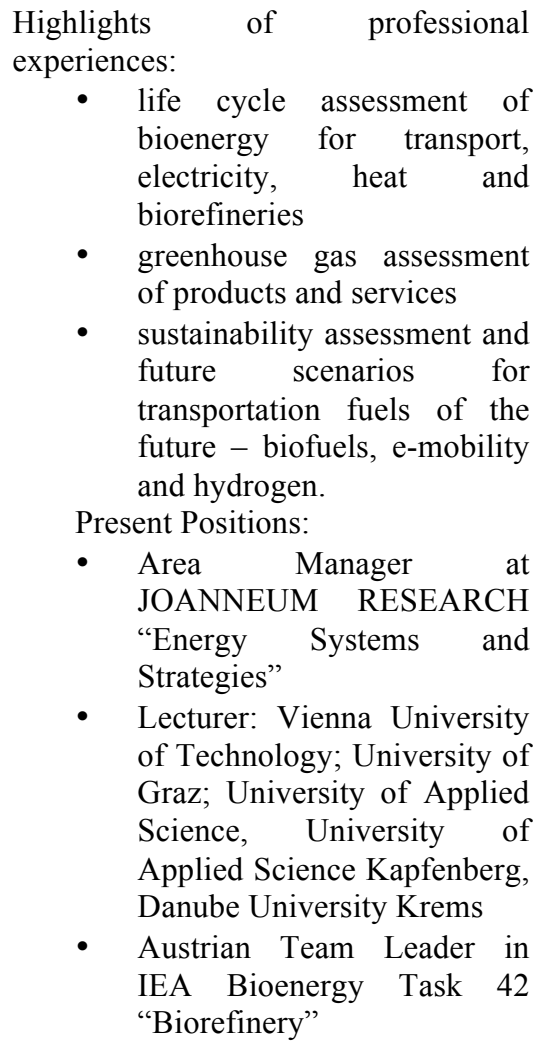

